\title{
PERAN DEWAN PENGAWAS DAN GOOD CORPORATE GOVENANCE PADA KINERJA BANK PERKREDITAN RAKYAT
}

\begin{abstract}
This research starts from the many problems that occur in Bank Perkreditan Rakyat (BPR). From 2014 to 2016 the number of BPRs closed or liquidated by the Financial Services Authority (OJK) in the Deposit Insurance Corporation (LPS) report there are 14 BPRs. Based on the background of the problem, this research will examine the role of supervisory board and GCG on the performance of BPR in Gianyar Regency.

This research will be conducted in Gianyar Regency. The sample is the head of the BPR, the finance department and the supervisory board of the BPR. Research sample 34 BPR and respondents were 105 respondents. Data were collected by disseminating research questionnaires. Analysis technique using multiple regression method. The results of the Supervisory Board's research did not affect the performance of BPR in Gianyar Regency while GCG had a positive effect on the performance of BPR In Gianyar Regency. The suggestion of this research is to add other supervisors such as commissioners, audit committees or independent auditors as one of the independent parties that may affect the performance of BPR.
\end{abstract}

Keywords: Supervisory Board, CGC, BPR Performance

Abstrak

Penelitian ini dimulai dari banyaknya masalah yang terjadi di Bank Perkreditan Rakyat (BPR). Sejak tahun 2014 sampai 2016 jumlah BPR yang ditutup atau dilikuidasi oleh Otoritas Jasa Keuangan (OJK) dalam laporan Lembaga Penjamin Simpanan (LPS) ada 14 BPR. Berdasarkan latar belakang masalah tersebut penelitian ini akan menguji peran dewan pengawasan dan GCG terhadap kinerja BPR di Kabupaten Gianyar. Penelitian ini akan dilakukan di Kabupaten Gianyar. Sampel adalah Kepala BPR, Bagian keuangan dan dewan pengawas BPR. Sampel penelitian 34 BPR dan responden sebanyak 105 responden. Data dikumpulkan dengan menyebarkan kuesioner penelitian. Teknik analisis menggunakan metode regresi berganda. Hasil penelitian Dewan Pengawas tidak berpengaruh terhadap kinerja BPR di Kabupaten Gianyar sedangnkan GCG berpengaruh positif terhadap kinerja BPR Di Kabupaten Gianyar. Saran penelitian ini adalah menambahkan pengawas yang lain seperti dewan komisaris, komite audit atau auditor independen sebagai salah satu pihak independen yang mungkin dapat mempengaruhi kinerja BPR.

Kata kunci: Dewan Pengawas, CGC, Kinerja BPR

\section{PENDAHULUAN}

Peran Perbankan dalam perekonomian sangat penting khusus berhubungan dengan perputaran uang. UU Nomor 10 Tahun 1998, menjelaskan bahwa terdapat dua jenis bank yang telah diakui oleh Bank Indonesia yaitu Bank Umum dan Bank Perkreditan Rakyat (BPR). Bank Perkreditan Rakyat (BPR) menyediakan produk 
keuangan yang serupa dengan bank umum ternyata memiliki penetrasi yang lebih baik khususnya untuk usaha mikro dan kecil. BPR menempati posisi yang penting dalam perekonomian rakyat, mengingat tingginya kebutuhan masyarakat dalam pinjaman dana, baik dana yang akan digunakan sebagai investasi, pendidikan dan lain sebagainya. Keberadaan BPR sangat membantu usaha kecil dan menengah karena dapat melayani masyarakat yang sulit mengakses bank umum didaerah atau desa. Bali merupakan salah satu provinsi yang masyarakatnya sadar akan pentingnya lembaga keuangan yang memudahkan usaha mereka. Kabupaten Gianyar merupakan salah satu wilayah yang sedang berkembang, hal tersebut terihat dari laju pertumbuhan Kabupaten Gianyar PDRB atas dasar harga konstan yang terus mengalami peningkatan. Data BPR yang tersebar diseluruh Bali menurut Bank Indonesia pada November 2016 sejumlah 137 BPR, dimana 28 BPR berada di Kabupaten Gianyar. Bank Perkreditan Rakyat yang terdapat di Kabupaten Gianyar tercatat menjadi BPR yang memiliki jumlah terbanyak kedua di Bali, sehingga potensi pemberian kredit kepada masyarakat cukup tinggi. Hal tersebut mewajibkan BPR untuk meningkatkan kinerja usahanya.

Masalah yang muncul saat ini adalah setiap tahun masih ada BPR yang harus dilikuidasi. Ditahun 2016 awal ada 4 BPR yang sudah dilikuidasi Otoritas Jasa Keuangan (OJK) yaitu BPR Dana Niaga Mandiri, BPR Syariah Al Hidayah, BPR Mitra Bunda Mandiri, BPR Agra Arthaka. OJK dan Lembaga Penjaminan Simpanan (LPS) tidak merinci penyebab BPR di likuidasi namun kondisi keuangan BPR yang menurun sangat signifikan dibandingkan dengan kondisi tahun sebelumnya mencerminkan keadaan BPR tidak sehat. Banyak faktor yang menyebabkan kinerja BPR menjadi masalah sehingga berujung pada pencabutan izin usaha. Menurut OJK dan Perhimpunan Bank Perkreditan Rakyat Indonesia (Perbarindo) kebanyakan BPR yang dicabut izinnya bukan karena kalah dalam persaingan melainkan lebih disebabkan oleh kecurangan (fraud) yang dilakukan oleh pengurus BPR sendiri. Fraud banyak terjadi salah satunya karena BPR tidak melaksanakan tata kelola perusahaan yang baik atau good corporate governance(GCG) dan kurangnya pengawasan. Kurangnya pengawasan dan tidak adanya penerapan GCG membuat banyak BPR melakukan fraud. Kedudukan dewan komisariat atau dewan pengawas di BPR sangat penting dan stategis karena fungsinya sebagai pengawasan atas kebijakan dan jalannya operasional BPR serta member nasehat pada direksi. Berdasarkan pemeriksaan OJK dilapangan dewan pengawas di BPR masih perlu ditingkatkan. Keberadaan Dewan pengawas bukan hanya sebagai pelengkap struktur organisasi saja. Komisaris harus bertindak independen dalam menjalankan fungsinya terutama terhadap kemungkinan adanya intervensi pemegang saham dalam operasional bank. Berhasilnya operasional BPR sangat tergantung juga pada efektifitas dan peran dewan pengawas dalam kinerja direksi. OJK telah mengatur tugas dewan pengawas dalam Peraturan Otoritas Jasa Keuangan. Selain peran dewan pengawasan GCG merupakan suatu tantangan BPR dimasa depan.

Penerapan GCG tidak hanya menghindari BPR dari potensi fraud tetapi juga dapat meningkatkan kinerja keuangan BPR. Penerapan GCG penting karena resiko dan tantangan yang dihadapi BPR tidak hanya berasal dari eksternal tapi juga internal BPR sendiri. Penerapan praktik GCG tidak sebatas ketentuan regulasi tapi menjadi kebutuhan yang mendesak terhadap perkembangan BPR dimasa depan. Komitmen BPR terhadap pernerapan GCG menjauhkan BPR dari masalah resiko tinggi yang berpotensi menjadikan BPR tidak sehat. Menurut KNKG (Komite Nasional Kebijakan Governance) terdapat lima prinsip GCG yaitu 
transparansi, akuntabilitas, responsibilitas, independensi, dan kewajaran. Penerapan prinsip-prinsip GCG telah dijadikan acuan oleh negara-negara di dunia termasuk Indonesia. Prinsip-prinsip tersebut diharapkan dapat menghasilkan keputusan yang lebih optimal dan jika tata kelola perusahaan baik, hal tersebut menunjukkan kecenderungan tanggung jawab perusahaan yang lebih besar (Rambo, 2013). Penerapan good corporate governance diharapkan dapat memberi manfaat dapat meningkatkan efisiensi operasional perusahan, serta lebih meningkatkan pelayanan kepada stakeholder perusahaan diharapkan dapat meningkatkan kinerjanya melalui penerapan proses pengambilan keputusan yang lebih baik dan perusahaan dapat meningkatkan corporate value dengan memperoleh dana pembiayaan yang lebih murah.

Pengukuran kinerja menurut Bank Indonesia mengacu pada unsur-unsur Capital, Asset Quality, Management, Earning, Liquidity (CAMEL). CAMEL digunakan untuk mengukur kinerja keuangan terhadap kegiatan operasionalnya dengan satu tingkat presentase tertentu yang telah ditetapkan sehingga dapat diketahui tingkat kesehatan bank dalam bentuk peringkat komposit (Lestari, 2009). Pengukuran kinerja perusahaan yang terlalu ditekankan pada sudut pandang finansial sering menghilangkan sudut pandang lain yang tentu saja tidak kalah pentingnya (Ciptani, 2000). Pengukuran kinerja perusahaan di dunia perbankan yang kompetitif seperti sekarang ini menuntut suatu pengukuran kinerja dari aspek keuangan dan aspek nonkeuangan.

Sistem pengukuran kinerja yang dirancang oleh Robert dan David yang dikenal sebagai balanced scorecard. Balanced Scorecard memiliki keistimewaan dalam hal pengukurannya yang komprehensif dengan menilai kinerja dari empat perspektif, yaitu perspektif keuangan, perspektif pelanggan, perspektif proses bisnis internal, serta perspektif pembelajaran dan pertumbuhan. Menggunakan balanced scorecard perusahaan bisa melangsungkan kehidupannya dalam jangka panjang karena balanced scorecard tidak hanya mengukur kinerjanya dari sisi keuangan saja tapi dari sisi non keuangan juga (Nita, 2007).

Berdasarkan latar belakang masalah penelitian adalah bagaimana pengaruh dewan pengawas dan good corporate governance (GCG) yang terdiri dari transparansi, akuntabilitas, responsibilitas, independensi, dan kewajaran pada kinerja Bank Perkreditan Rakyat (BPR) di Kabupaten Gianyar.

\section{TINJAUAN LITERATUR DAN PENGEMBANGAN HIPOTESIS}

\section{Pengaruh Peran Dewan Pengawas terhadap Kinerja BPR}

Penelitian yang membahas tentang pengaruh peran dewan komisaris terhadap kinerja perusahaan. Penelitian terdahulu yang melakukan penelitian dengan variabel ukuran dewan komisaris terhadap kinerja perusahaan adalah seperti penelitian yang dilakukan oleh Muktiyanto (2011), Widagdo dan Chariri (2014) yang menunjukkan hubungan yang positif signifikan. Dewayanto (2010) dan Puspitasari dan Ernawati (2010) menunjukkan bahwa antara ukuran dewan komisaris terhadap kinerja perusahaan terdapat hubungan yang negatif signifikan. Nugrahani dan Nugroho (2010), Manik (2011), dan Widiawati (2013) melakukan penelitian dengan salah satu variabelnya adalah komisaris independen. Hasil penelitian dari beberapa peneliti diatas menunjukkan bahwa komisaris independen berpengaruh positif signifikan terhadap kinerja perusahaan. 
Berdasarkah hasil penelitian tersebut maka hipotesis penelitian adalah:

\section{$\mathbf{H}_{1}$ : Peran Dewan Pengawas berpengaruh terhadap Kinerja BPR}

\section{Pengaruh GCG Terhadap Kinerja BPR}

Menurut Dewi dan Asri (2014) prinsip good corporate governance berpengaruh positif terhadap kinerja. Rahmandy (2012) melakukan penelitian mengenai penerapan prinsip good coorporate governance (GCG) pada PT BankTabungan Negara (Persero) Tbk mengatakan bahwa penerapan prinsip GCG akan meningkatkan kinerja perusahaan. Hal yang serupa juga dipaparkan dalam penelitian Pratiwi (2014), transparansi berpengaruh positif terhadap kinerja. Berdasarkan penelitian sebelumnya maka hipotesis penelitian sebagai berikut.

\section{$\mathrm{H}_{2}$ : $\mathbf{G C G}$ berpengaruh terhadap Kinerja BPR}

\section{METODE PENELITIAN}

Lokasi penelitian ini adalah Bank Perkreditan Rakyat di Kabupaten Gianyar. Objek penelitian ini adalah Dewan Pengawas, Good Corporate Governance, dan Kinerja BPR. Populasi dalam penelitian ini adalah 34 Bank Perkreditan Rakyat (BPR) di wilayah Gianyar. Data yang digunakan adalah data primer dengan menyebarkan kuesioner penelitian. Penelitian ini menggunakan dua jenis variabel yaitu: Variabel terikat atau dependent variabel $(\mathrm{Y})$ adalah kinerja berbasis balanced scorecard $(\mathrm{Y})$ dan Variabel bebas atau independent variabel $(\mathrm{X})$ adalah dewan pengawas $\left(\mathrm{X}_{1}\right)$ dan prinsip-prinsip good corporate governance yang terdiri dari 5 (lima) variabel yaitu transparansi $\left(\mathrm{X}_{2}\right)$, akuntabilitas $\left(\mathrm{X}_{3}\right)$, responsibilitas $\left(\mathrm{X}_{4}\right)$, independensi $\left(\mathrm{X}_{5}\right)$, dan kewajaran $\left(\mathrm{X}_{6}\right)$. Pengukuran variable penelitian adalah sebagai berikut:

Pengukuran kinerja berbasis balanced scorecard menggunakan 12 pernyataan yang terdiri dari empat perspektif, yaitu perspektif keuangan, perspektif pelanggan, perspektif proses bisnis internal, serta perspektif pembelajaran dan pertumbuhan. Pada penelitian ini menggunakan skala 4 titik. Responden menyatakan, dengan memberi tanda silang nomor yang tepat di sebelah masing-masing pernyataan. Dewan Pengawas dalam penelitian ini diukur dengan menggunakan jumlah seluruh anggota dewan Pengawas dalam BPR ini mengadopsi penelitian terdahulu seperti penelitian Dewayanto (2010), Puspitasari dan Ernawati (2010), Muktiyanto (2011) dan Widagdo dan Chariri (2014).

Good Corporate Governance di ukur dengan beberapa aspek yaitu: Aspek transparansi diukur dengan 4 pernyataan mengenai sistem akuntansi dalam perusahaan, pengembangan teknologi, informasi manajemen, dan manajemen resiko, serta publikasi informasi keuangan dan informasi lain yang material mengenai perusahaan. Aspek akuntabilitas diukur dengan 4 pernyataan mengenai komite audit, peran dan fungsi auditor internal dan eksternal, serta sistem penilaian kinerja dalam perusahaan. Aspek responsibilitas atau pertanggungjawaban diukur dengan 4 pernyataan mengenai tanggung jawab sosial perusahaan, profesionalisme dan etika bisnis, serta lingkungan bisnis dalam suatu perusahaan. Aspek independensi diukur dengan 4 pernyataan mengenai penggunaan tenaga ahli dalam perusahaan, pengaruh pihak luar, benturan kepentingan, dan aktifitas perusahaan. Aspek kewajaran diukur dengan 4 pernyataan mengenai aturan perusahaan untuk melindungi kepentingan pemegang saham, peran dan tanggung jawab komisaris dan manajemen, serta kewajaran dalam pengungkapan sistem informasi. 
Teknik Analisis Data tahap pertama melakukan Uji Instrumen Penelitian dengan uji validitas dan ujian reliabilitas. Tahap kedua uji asumsi klasik yang merupakan syarat yang harus dipenuhi pada analisis regresi berbasis ordinary least Square (OLS). Pada penelitian ini pengujian asumsi klasik dilakukan untuk memastikan bahwa model regresi yang digunakan tidak terdapat heteroskendastisitas dan nilai residual data yang dihasilkan berdistribusi normal. Uji hipotesis pada penelitian ini menggunakan analisis regresi linear berganda yang diukur dari uji statistik $t$, Uji statistik F, dan koefisien determiniasi $\left(R^{2}\right)$

\section{HASIL DAN DISKUSI}

Penelitian ini dilakukan di BPR Kabupaten Gianyar. Metode penentuan sampel yang digunakan dalam penelitian ini adalah metode sampling jenuh dimana semua populasi digunakan sebagai sampel. BPR di Kabupaten Gianyar sebanyak 34 BPR seluruhnya digunakan. Penelitian ini menggunakan responden sebanyak 105 orang yang terdiri dari 34 Direktur, 37 Staf bagian keuangan dan umum, 37 Dewan Pengawas BPR. Ringkasan pengiriman dan pengembalian kuisioner penelitian ini ditunjukkan dalam Tabel 1. Secara keseluruhan kuisioner dapat digunakan dengan baik.

\section{Profil Responden}

Karekteristik demografi responden dalam penelitian ini merupakan profil dari 105 partisipasi yang merupakan responden penelitian. Karakteristik responden ini meliputi jabatan, jenis kelamin, umur, dan pendidikan terakhir dapat dilihat pada tabel 2.

Jabatan mencerminkan kedudukan seseorang di dalam perusahaan. Responden yang menjabat sebagai Direktur berjumlah 34 orang (32 persen), sebagai bagian keuangan berjumlah 34 orang (32 persen) dan sebagai Dewan Pengawas sebanyak 37 orang (36 persen). Ini berarti responden penelitian jumlah yang terbanyak adalah dewan pengawas BPR dan terlibat dalam kinerja dan bagian dari GCG BPR di Kabupaten Gianyar.

Jenis kelamin dapat digunakan untuk mengetahui proporsi responden laki-laki dan perempuan pada BPR di Kabupaten Gianyar. Responden berjenis kelamin laki-laki sebanyak 68 orang ( 65 persen) dan responden berjenis kelamin wanita sebanyak 37 orang (35persen). Dapat disimpulkan yang menduduki jabatan Direktur, Bagian Keuangan dan Dewan Pengawas mayoritas adalah laki-laki.

Usia digunakan untuk mengetahui rentang usia responden yang bekerja pada BPR di Kabupaten Gianyar. Sebanyak 49 orang (47 persen) memiliki usia $\leq 30$ tahun dan sebanyak 56 orang (53 persen) memiliki usia lebih dari 30 tahun. Artinya sebagian besar responden berusia diatas 30 tahun.

Pendidikan terakhir digunakan sebagai indikator untuk mengetahui tingkat pendidikan terakhir yang ditempuh responden. Responden dengan pendidikan terakhir SMA sebanyak 13 orang (12 persen), Diploma sebanyak 14 orang (13 persen), S1 sebanyak 63 orang (60 persen) dan 15 orang (15 persen) responden dengan pendidikan terakhir S2. Mayoritas responden yang menduduki jabatan direktur, bagian keuangan dan dewan pengawas adalah berpendidikan S1.

Pengujian yang digunakan untuk menguji instrumen penelitian ada dua, yaitu uji validitas dan reliabilitas. Hasil uji validitas menunjukkan bahwa seluruh variabel memiliki nilai koefisien korelasi dengan skor total seluruh item pernyataan lebih besar dari 0,30. Hal ini menunjukkan bahwa butir-butir pernyataan dalam 
instrument penelitian tersebut valid. Hasil uij reliabel menunjukkan bahwa seluruh instrumen penelitian yaitu memiliki koefisien Cronbach's Alpha lebih dari 0,60. Hal ini dapat dikatakan bahwa semua instrumen reliabel sehingga dapat digunakan untuk melakukan penelitian.

\section{Deskripsi Variabel Penelitian}

Variabel GCG dalam penelitian ini merupakan variabel bebas yang diukur dengan menggunakan 20 pernyataan. Secara rinci hasil penelitian mengenai persepsi responden terhadap variabel GCG disajikan pada Tabel 3.

Tabel 3 menunjukkan bahwa rata-rata skor dari 20 pernyataan responden mengenai GCG. Jawaban Responden yang meliputi unsur transparansi, akuntabilitas, Responsibilitas, Independensi dan kewajaran yang merupakan ukuran dari variable GCG. Berdasarkan jawaban atas kuesioner penelitian, sebagaian besar responden setuju dan sangat setuju untuk melakukan transparansi melalui pengembangan system akuntansi berdasarkan standar, teknologi informasi manajemen, pengembangan manajemen resiko dan publikasi laporan keuangan. Setelah dikonfirmasi lebih lanjut BPR dibawah pengawasan BI telah melakukkan hal tersebut sehingga aspek transparansi dapat dicapai dengan maksimal.

Hasil jawaban kuesioner atas aspek akuntanbilitas adalah responden sebagian besar menjawab setuju. Aspek Akuntanbilitas dalam hal membentuk komite audit terdapat 3 persen jawaban sangat tidak setuju, 6 persen tidak setuju, 16 persen ragu-ragu, 52 persen setuju dan 24 persen sangat setuju. Hal ini menunjukan walaupun sebagai besar setuju tetapi masih ada responden yang sangat tidak setuju dalam pembentukan komite audit setelah dikomfirmasi pembentukan komite audit dipandang tidak perlu karena BPR telah memiliki dewan pengawas intern dan ekstenal. Aspek akuntanbiltas yang lain mengunakan auditor eksternal dan berkualitas sebagai besar setuju dan sangat setuju walaupun masih terdapat 12 persen jawaban raguragu.

Hasil Jawaban responden terhadap responsibilitas adalah sebagaian besar jawaban responden setuju dan sangat setuju. 14 persen jawaban ragu-ragu atas pertimbangan tanggung jawab sosial. Beberapa BPR ragu-ragu atas aspek tanggung jawab sosial kemungkinan karena masih kurangnya dana yang dimiliki oleh BPR untuk melakukan tanggungjawab sosial.

Aspek GCG selanjutnya adalah independensi dimana BPR dituntut untuk independen misalnya menggunakan tenaga ahli dalam hal keuangan dan pihak luar. Hasil jawaban kuesioner penelitian sebagai besar setuju independensi penting. Tetapi ada juga yang masih tidak setuju menggunakan tenaga ahli dan pihak luar 6 persen dan 4 persen.

Aspek kewajaran merupakan unsur penting dalam GCG. Kewajaran aturan perusahaan untuk melindungi kepentingan karyawan 60 persen responden setuju dan 13 persen sangat setuju. Menetapkan peran dan tanggung jawab komisaris 52 persen setuju dan 27 persen sangat setuju. Aspek wajar dalam mengungkapkan system informasi keuangan 57 persen responden setuju dan 12 persen sangat setuju. Kesimpulan dari hasil jawaban kuesioner GCG respoden memberikan respon positif.

Tabel 4 . menjelaskan kinerja balanced scorecard berdasarkan dua aspek yaitu aspek keuangan dan non 
keuangan. Hasil jawaban responden terhadap aspek keuangan yang terdiri dari laporan keuangan yang tepat waktu dan diaudit oleh akuntan yang independen adalah 49 persen setuju, 50 persen sangat setuju, dan 1 persen tidak setuju dan ragu-ragu. Jawaban kuesioner atas adanya analisis rentabilitas 42 persen setuju, 55 persen sangat setuju dan 4 persen ragu-ragu. Jawaban atas adanya peningkatan laba dan efisiensi biaya adalah 49 persen setuju dan 48 persen sangat setuju serta 4 persen ragu-ragu. Berdasarkan hasil jawaban tersebut maka kinerja keuangan memegang peranan penting dalam BPR.

Tabel 4 juga menjelaskan kinerja non keuangan dalam perspektif pelanggan yang ditunjukan dengan jumlah pelanggan yang setiap tahun bertambah hasil jawaban responden 54 persen setuju dan 45 persen sangat setuju. Perspektif pelanggan dilihat dari Citra dan nama baik organisasi jawaban responden 38 persen setuju dan 54 persen sangat setuju, 10 persen ragu-ragu. Perspektif pelanggan yang menyatakan kurang dari 10 persen pelanggan mengeluh terhadap pelayanan hasil jawaban kuesioner 50 pesen setuju dan 49 persen sangat setuju. 1 persen tidak setuju dan ragu-ragu.

Kinerja non keuangan dalam perspesktif proses bisnis internal meliputi melakukan kegiatan inovasi produksi jawaban responden 43 persen setuju, 54 persen sangat setuju dan 4 persen ragu-ragu. Mengintensifkan program budaya kepatuhan, peningkatan kualitas dan monitoring tindakan yang bertanggung jawab, jawaban responden 1 persen tidak setuju dan ragu-ragu, 46 persen setuju, 53 persen sangat setuju. Aspek peningkatan kepuasan nasabah 4 persen ragu-ragu, 44 persen setuju dan 53 persen sangat setuju. Rata-rata jawaban responden untuk aspek perspektif proses bisnis internal adalah sangat setuju.

Perspektif pembelajaran dan pertumbuhan meliputi kepuasan karyawan atas peningkatan kompetensi SDM, Jawaban responden 4 persen ragu-ragu, 37 persen setuju dan 40 persen sangat setuju. Penggunaan dan pengembangan pemanfaatan system teknologi informasi 2 persen ragu-ragu, 53 persen setuju, 46 persen sangat setuju. Hubungan yang komunikatif antara atasan dan bawahan maupun rekan kerja 10 persen responden ragu-ragu, 40 persen setuju dan 51 persen sangat setuju.

Penelitian ini juga melakukan Uji asumsi klasik untuk memastikan hasil yang diperoleh memenuhi asumsi dasar di dalam analisis regresi. Hasil uji asumsi klasik yang dilakukan dalam penelitian ini telah terpenuhi dan dibebaskan dari asumsi klasik.

\section{Analisis Regresi Linear Berganda}

Analisis regresi linear berganda digunakan untuk mengetahui pengaruh dewan pengawas dan GCG terhadap kinerja BPR di kabupaten Gianyar. Hasil analisis regresi linear berganda dapat dilihat pada Tabel 5.

Berdasarkan hasil analisis regresi linier berganda seperti yang disajikan pada Tabel 5. maka persamaan strukturalnya adalah sebagai berikut :

$$
Y=19,075+0,846 X_{1}+0,393 X_{2}+\varepsilon
$$

Hasil uji statistik $t$ (uji hipotesis) menunjukan besar pengaruh variabel independen secara individual dalam menerangkan variasi variabel dependen. Hasil uji t dapat dilihat pada tabel 5.11. Nilai thitung pada variabel dewan pengawas adalah sebesar 1,251 dengan tingkat signifikansi 0,214. Dengan menggunakan batas signifikansi 0,05, maka signifikansi tersebut diatas taraf 5 persen yang berarti nilai Ho diterima dan $\mathrm{H} 1$ ditolak artinya bahwa dewan pengawas tidak mempengaruhi kinerja BPR di kabupaten Gianyar. Nilai t hitung pada 
variabel GCG adalah sebesar 8,007 dengan tingkat signifikansi 0,000. Dengan menggunakan batas signifikansi 0,05, maka signifikansi tersebut dibawah taraf 5 persen yang berarti nilai Ho ditolak dan $\mathrm{H} 1$ diterima. bahwa GCG berpeangaruh positif dan signifikan terhadap kinerja BPR di Kabupaten Gianyar.

Pada penelitian ini, koefisien determinasi yang digunakan adalah $R$ Square yang sudah disesuaikan atau Adjusted $R^{2}$ karena nilai adjusted $R^{2}$ dapat naik atau turun apabila satu variabel independen ditambahkan ke dalam model. Tabel 6 menunjukkan hasil uji koefisien determinasi $\left(R^{2}\right)$.

Berdasarkan hasil uji determinasi diketahui bahwa nilai adjusted Rsquare sebesar 0,440, yang mengandung arti bahwa 44 persen variasi besarnya kinerja BPR bisa dijelaskan oleh variasi dewan pengawas dan GCG. Sedangkan sisanya 56 persen lainnya dijelaskan oleh variabel lain di luar yang diteliti.

Uji F digunakan untuk mengetahui kelayakan dari model regresi linear berganda sebagai alat analisis yang menguji pengaruh variabel independen terhadap variabel dependen. Apabila tingkat signifikansi $F \leq$ $a=0,05$ maka hubungan antar variabel bebas adalah signifikan mempengaruhi kualitas laporan keuangan pemerintah daerah sebagai variabel terikat, sebaliknya jika tingkat signifikansi $F>a=0,05$ maka hubungan antar variabel bebas adalah tidak signifikan mempengaruhi kualitas laporan keuangan pemerintah daerah sebagai variabel terikat. Tabel 7 menyajikan hasil uji F penelitian.

Berdasarkan Tabel 7, nilai signifikansi uji $\mathrm{F}$ yaitu sebesar 0,000 yang lebih kecil dari 0,05. Hal ini berarti model yang digunakan pada penelitian ini adalah layak. Hasil ini memberikan makna bahwa kedua variabel independen mampu memprediksi atau menjelaskan kinerja BPR di kabupaten Gianyar.

\section{SIMPULAN}

Berdasarkan hasil pembahasan dan analisis data penelitian maka dapat disimpulkan bahwa dewan pengawas tidak mempengaruhi kinerja BPR di Kabupaten Gianyar. Dewan pengawas sebagai pihak independen di BPR belum maksimal menjalani fungsinya sebagai pengawas BPR mungkin karena BPR juga memiliki pengawas yang lebih kuat yaitu Bank Indonesia. Sedangkan untuk variable GCG berpengaruh positif terhadap kinerja BPR. Artinya semakin tinggi prinsip-prinsip GCG yang meliputi Transparansi, akuntabilitas, responsibilitas, independensi maka kinerja keuangan dan non keuangan BPR di kabupaten Gianyar semakin baik.

Saran penelitian selanjutnya adalah alat analisis yang digunakan adala PLS. Pihak independen tidak hanya dewan pengawas tetapi lebih lengkap lagi misalnya komisaris independen, auditor eksternal, komite audit. Analisis yang digunakan tidak lagi manual tetapi bisa secara online.

\section{DAFTAR REFERENSI}

Araujo, Elidio De., Budiman Christiananta. 2013 Confirmatory Factor Analysis On Strategic Leadership, Corporate Culture, Good Corporate Governance And Company Performance. Part-Il: Social Sciences and Humanities, 4(4).

Ciptani, Monika Kussetya. 2000. Balanced Scorecard Sebagai Pengukuran Kinerja Masa Depan: Suatu Pengantar. Jurnal Akuntansi \& Keuangan 2 (1), h: 21 - 35. 
Chaarani, Hani El. 2014. The Impact Of Corporate Governance On The Performance Of Lebanese Banks. The International Journal of Business and Finance Research 8(5).

Chen, C. C. and K. Jones. 2009. Are Employees Buying The Balanced Scorecard?. Management Accounting Quarterly pp. 36-44.

Dewayanto, Totok. 2010. Pengaruh mekanisme good corporate governance terhadap kinerja perbankan nasional. Fokus Ekonomi. Vol.5, No.2. 104-123.

Dewi, K. Krismaya dan IGA M. Asri Dwija Putri. 2014. Pengaruh Penerapan Prinsip-Prinsip GCG Pada Kinerja Keuangan Lembaga Perkreditan Desa Kabupaten Gianyar. E-Jurnal Akuntansi Universitas Udayana 7 (3), h:559-573.

Dudin, Mihail Nikolaevich dan Evgenia Evgen'evna Frolova. 2015. The Balanced Scorecard as a Basis for Strategic Company Management in the Context of the World Economy Transformation. Asian Social Science, Published by Canadian Center of Science and Education, 11 (3).

Hayati, N. R., Muclis, T. I., and Oktaviani, F. 2009. Comparison Analysis of Financial Performance on Shariah Banking (Case Study In Indonesia and Malaysia). Journal of International Business Academics Consortium Academy of Taiwan Information Systems Research college of Business National Taipe University.

Ismail Solihin. 2008. Corporate Social Responsibility from Charity to Sustainability. Bandung: Salemba Empat Ittner, Christopher D., David F. Larcker, and Marshall W. Meyer. 1997. Performance, Compensation, And The Balanced Scorecard. The Wharton School The University of Pennsylvania

Jensen, M.C., and Meckling, W.H. 1976. Theory of The Firm: Manajerial Behavior, Agency Cost, and Ownership Strukture. Journal of Financial Economic 3, pp: 305-360

Komite Nasional Kebijakan Governance (KNKG). 2006. Pedoman Umum Good Corporate Governance Indonesia. Jakarta.

Komite Nasional Kebijakan Governance (KNKG). 2012. Prinsip Dasar Pedoman Good Corporate Governance Perbankan Indonesia. Jakarta.

Khozein, Ali. 2012. Balanced Scorecard Should be Attention More in Organization. International Journal of Research in Management Vol.1, Iss.2, ISSN 2249-5908.

Krenn, Mario. 2014. Decoupling as a Sustainable Firm Response to Pressures for Convergence and Divergence in Corporate Governance: The Case of Codes of Good Corporate Governance. Journal of Management Policy and Practice, 15 (4).

Lestari, Venny Dwi. 2009. Analisis Tingkat Kesehatan Bank-Bank Pemerintahan dengan Menggunakan CAMELS dan Analisis Deskriminan Periode 2006-2008. Journal Akuntansi Universitas Gunadharma.

Lipe, Marlys Gascho and Steven E. Salterio. 2000. The Balanced Scorecard: Judgmental Effects of Common and Unique Performance Measures. The Accounting Review 75(2).

Manik, Tumpal. 2011. Analisis pengaruh kepemilikan manajemen, komisaris independen, Komite audit, umur perusahaan terhadap kinerja keuangan. JEMI. Vol.2, No.2. 25-36.

Muktiyanto, Ali. 2011. Pengaruh interdependensi mekanisme corporate governance terhadap kinerja perbankan. Jurnal Akuntansi dan keuangan Indonesia. Vol.8, No.2. 197-213. 
Muhammad Arief Effendi. 2009. The Power of Good Corporate Governance Teori dan Implementasinya. Jakarta: Salemba Empat.

Mulyadi. 2007. Akuntansi Manajemen. Edisi ke-3. Jakarta: Salemba Empat.

Nita, Yuanita. 2007. Penerapan Balanced Scorecard Sebagai Alternatif Pengukuran Kinerja Perusahaan. Skripsi Sekolah Tinggi Ilmu Ekonomi, Indonesia.

Nugrahani, Tri Siwi dan Nugroho, Fajar Agus. 2010. Pengaruh komisaris independen dan pengungkapan sukarela terhadap kinerja perusahaan. Karisma. Vol.4, No.2. 132-141.

Otoritas Jasa Keuangan. 2015. Alamat Bank Perkreditan Rakyat. http://www.ojk.go.id/data-alamat-bprk. Diunduh tanggal 15, bulan April, tahun 2015.

Otoritas Jasa Keuangan. 2015. Bank Perkreditan Rakyat. http://www.ojk.go.id/bank-perkreditan-rakyat. Diunduh tanggal 03, bulan Juni, tahun 2015.

Peni, Emilia, Stanley D. Smith, and Sami Vahamaa. 2013. Bank Corporate Governance and Real Estate Lending During the Financial Crisis. JRER, 35 (3).

Peraturan Bank Indonesia Nomor 8/26/PBI/2006 Tanggal 5 Oktober 2006 Tentang Perubahan atas Peraturan Bank Indonesia Nomor 8/4/PBI/2006 Tentang Pelaksanaan GCG bagi Bank Umum.

Pratiwi, Ni Luh Putu Andriyani. 2014. Pengaruh Prisip-Prinsip Good Corporate Governance Terhadap Kinerja Berbasis Balanced Scorecard. Skripsi Fakultas Ekonomi dan Bisnis Universitas Udayana, Bali.

Puspitasari, Filia dan Ernawati, Endang. 2010. Pengaruh mekanisme corporate governance Kinerja keuangan badan usaha. Jurnal Manajemen Teori dan Terapan

Rambo, Charles M. 2013. Influence Of The Capital Markets Authority's Corporate Governance Guidelines On Financial Performance Of Commercial Banks In Kenya. The International Journal of Business and Finance Research, 7 (3).

Sugiyono. 2013. Metode Penelitian Bisnis. Bandung: Alfabeta.

Sundari, Sri. 2011. Hubungan Balance Scorecard sebagai Pengukuran Kinerja Pada Critical Sucsess Factors Perusahaan.

Undang-Undang Nomor 10 Tahun 1998 Tentang Perubahan atas Undang-Undang Nomor 7 Tahun 1992 Tentang Perbankan.

Wahyuni, Sri. 2011. Analisis Balanced Scorecard Sebagai Alat Pengukuran Kinerja Pada PT. Semen Bosowa Maros. Universitas Hasanuddin.

Widagdo, Dominikus O.K dan Chariri, Anis. 2014. Pengaruh good corporate governance terhadap kinerja perusahaan. Diponegoro Journal of Accounting. Vol.3, No.3. 1-9.

. 2014. Kasus BPR Restu Artha Makmur Bermula dari Kredit. http://finansial.bisnis.com/ read/20140305/90/208056/kasus-bpr-restu-artha-makmur-bermula-dari-kredit-rp1-miliar. Diunduh pada tanggal 18, bulan April, tahun 2015.

- 2015. Gianyar dalam Angka. http://www.gianyarkab.go.id/index.php/profil/12/Gianyar-DalamAngka-2014. Diunduh pada tanggal 18, bulan Agustus, tahun 2015 


\section{LAMPIRAN}

Tabel 1. Rincian Pengiriman dan Pengembalian Kuesioner

\begin{tabular}{lcr}
\hline \multicolumn{1}{c}{ Keterangan } & Jumlah & Persentase \\
\hline Kuesioner yang disebarkan & 105 & $100 \%$ \\
\hline Kuesioner yang tidak lengkap & 0 & 0 \\
\hline Kuesioner yang dikembalikan & 105 & $100 \%$ \\
\hline Kuesioner yang digugurkan/tidak lengkap & 0 & 0 \\
\hline Kuesioner yang digunakan & 105 & $100 \%$ \\
\hline Tingkat pengembalian (respon rate) $=105 / 105 \times 100 \%=100 \%$ & &
\end{tabular}

Sumber: Data primer diolah, 2017

Tabel 2. Demografi Responden

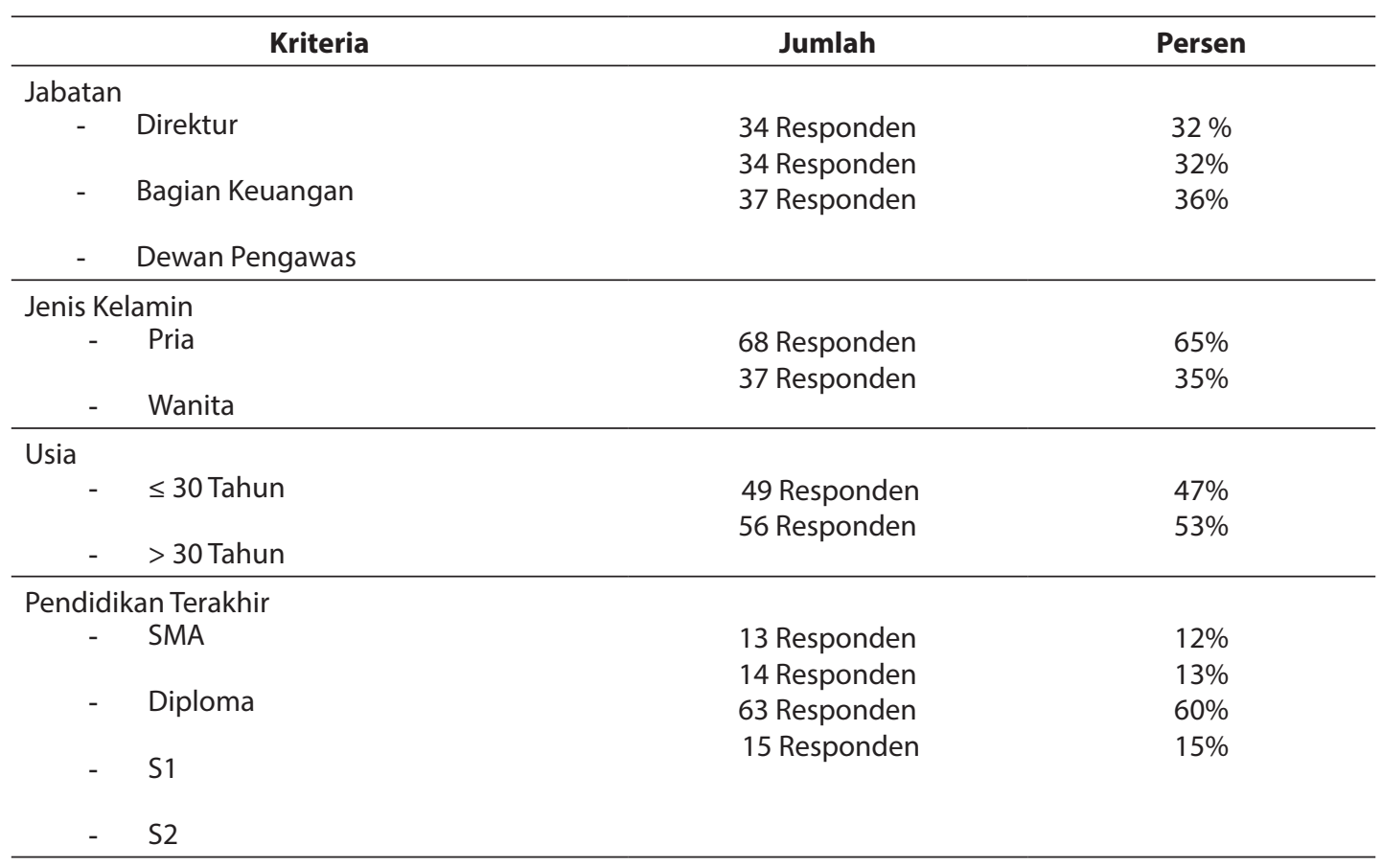

Sumber: Data primer diolah, 2017 
Tabel 3 Deskripsi Persepsi Responden Terhadap

Variabel Good Corporate Governance (GCG)

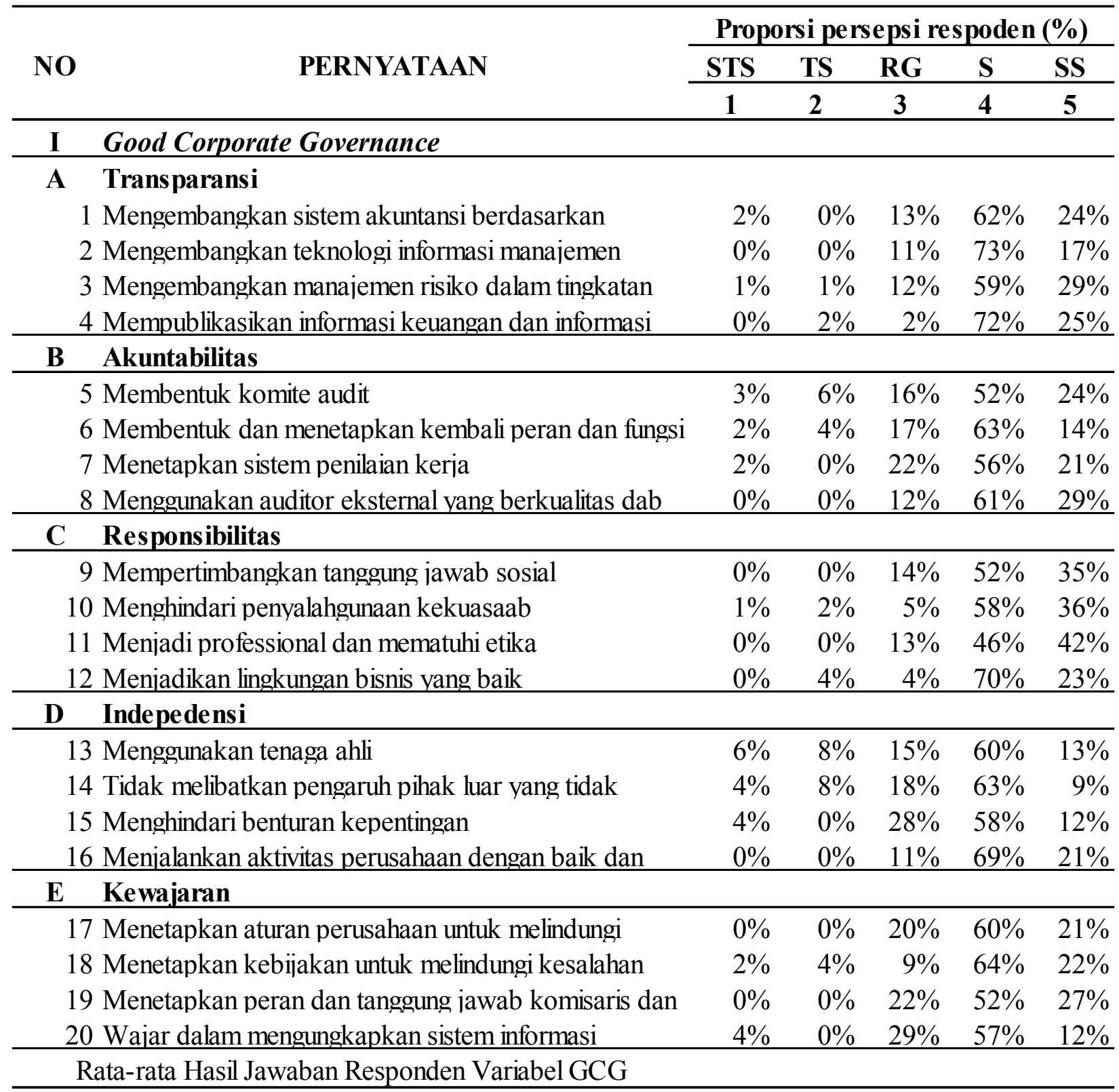

Sumber : data diolah (2017) 
Tabel 4 Deskripsi Persepsi Responden Terhadap Variabel Kinerja

\begin{tabular}{|c|c|c|c|c|c|c|}
\hline \multirow{3}{*}{ NO } & \multirow{3}{*}{ PERNYATAAN } & \multicolumn{5}{|c|}{ Proporsi persepsi respoden (\%) } \\
\hline & & \multirow{2}{*}{$\begin{array}{c}\text { STS } \\
1\end{array}$} & \multirow{2}{*}{$\begin{array}{c}\text { TS } \\
2 \\
\end{array}$} & \multirow{2}{*}{$\begin{array}{c}\mathbf{R G} \\
3 \\
\end{array}$} & \multirow{2}{*}{ S } & \multirow{2}{*}{$\begin{array}{c}\mathrm{SS} \\
\mathbf{5}\end{array}$} \\
\hline & & & & & & \\
\hline & \multicolumn{6}{|l|}{ Kinerja Balanced Scorecard } \\
\hline & A. Perspektif Keuangan & & & & & \\
\hline 1 & $\begin{array}{l}\text { Adanya laporan keuangan yang tepat waktu dan sudah } \\
\text { diaudit oleh pihak yang independen }\end{array}$ & $0 \%$ & $1 \%$ & $1 \%$ & $49 \%$ & $50 \%$ \\
\hline 2 & $\begin{array}{l}\text { Adanya analisis rasio rentabilitas keuangan yaitu ROA } \\
\text { dan ROE }\end{array}$ & $0 \%$ & $0 \%$ & $4 \%$ & $42 \%$ & $55 \%$ \\
\hline 3 & Adanya peningkatan laba dan efisiensi biaya. & $0 \%$ & $0 \%$ & $4 \%$ & $49 \%$ & $48 \%$ \\
\hline \multicolumn{7}{|c|}{ B. Perspektif Pelanggan } \\
\hline 4 & Jumlah pelanggan/nasabah LPD setiap tahun bertambah & $0 \%$ & $0 \%$ & $2 \%$ & $54 \%$ & $45 \%$ \\
\hline 5 & Citra dan nama organisasi baik. & $0 \%$ & $0 \%$ & $10 \%$ & $38 \%$ & $54 \%$ \\
\hline 6 & $\begin{array}{l}\text { Kurang dari } 10 \% \text { pelanggan/nasabah mengeluh terhadap } \\
\text { pelayanan }\end{array}$ & $0 \%$ & $1 \%$ & $1 \%$ & $50 \%$ & $49 \%$ \\
\hline \multicolumn{7}{|c|}{ C. Perspektif Proses Bisnis Internal } \\
\hline 7 & $\begin{array}{l}\text { Melakukan kegiatan inovasi produksi } \\
\text { Mengintensifkan program budaya kepatuhan, }\end{array}$ & $0 \%$ & $0 \%$ & $4 \%$ & $43 \%$ & $54 \%$ \\
\hline 8 & $\begin{array}{l}\text { peningkatan kualitas dan memonitor tindakan yang } \\
\text { bertanggung jawab }\end{array}$ & $0 \%$ & $1 \%$ & $1 \%$ & $46 \%$ & $53 \%$ \\
\hline 9 & Peningkatan atas kepuasan nasabah. & $0 \%$ & $0 \%$ & $4 \%$ & $44 \%$ & $53 \%$ \\
\hline \multicolumn{7}{|c|}{ D. Perspektif pembelajaran dan pertumbuhan } \\
\hline 10 & $\begin{array}{l}\text { Kepuasan karyawan atas peningkatan Kompetensi } \\
\text { SDM }\end{array}$ & $0 \%$ & $0 \%$ & $4 \%$ & $37 \%$ & $40 \%$ \\
\hline 11 & $\begin{array}{l}\text { Penggunaan dan pengembangan pemanfaatan Sistem } \\
\text { teknologi informasi }\end{array}$ & $0 \%$ & $0 \%$ & $2 \%$ & $53 \%$ & $46 \%$ \\
\hline 12 & $\begin{array}{l}\text { Hubungan yang komunikatif antara atasan dan bawahan } \\
\text { maupun rekan kerja }\end{array}$ & $0 \%$ & $0 \%$ & $10 \%$ & $40 \%$ & $51 \%$ \\
\hline
\end{tabular}

Sumber : data diolah (2017) 
Tabel 5. Hasil Analisis Regresi Linier Berganda

\begin{tabular}{|c|c|c|c|c|c|c|}
\hline \multirow{2}{*}{\multicolumn{2}{|c|}{ Model B }} & \multicolumn{2}{|c|}{$\begin{array}{l}\text { Unstandardized } \\
\text { Coefficients }\end{array}$} & \multirow[t]{2}{*}{$\begin{array}{l}\text { Standardized } \\
\text { Coefficients }\end{array}$} & \multirow[b]{2}{*}{$\mathrm{T}$} & \multirow[b]{2}{*}{ Sig. } \\
\hline & & Std. Error & Beta & & & \\
\hline \multirow[t]{3}{*}{1} & (Constant) & 19,075 & 3,899 & & 4,893 & ,000 \\
\hline & $\mathrm{X} 1$ & ,846 & 677 & ,098 & 1,251 & 214 \\
\hline & $X 2$ & 393 & ,049 & ,626 & 8,007 & ,000 \\
\hline \multicolumn{2}{|r|}{$\begin{array}{l}\text { R Square } \\
\text { F Statistik } \\
\text { Signifikansi }\end{array}$} & & & & \multicolumn{2}{|r|}{$\begin{array}{r}0.440 \\
39,992 \\
0,000\end{array}$} \\
\hline
\end{tabular}

Sumber : data diolah (2017)

Tabel. 6 Hasil Uji Koefisien Determinasi $\left(\mathbf{R}^{2}\right)$

\begin{tabular}{|c|c|c|c|c|}
\hline Model & R & R Square & $\begin{array}{c}\text { Adjusted R } \\
\text { Square }\end{array}$ & $\begin{array}{c}\text { Std. Error of the } \\
\text { Estimate }\end{array}$ \\
\hline 1. & $0,663^{\mathrm{a}}$ & 0,440 & 0,429 & 4,22827 \\
\hline
\end{tabular}

Sumber : Data diolah (2017)

Tabel 7. Hasil Uji F

\begin{tabular}{|c|c|c|}
\hline Model & F & Sig. \\
\hline Regression & 39,992 & 0,000 \\
\hline
\end{tabular}

Sumber Data diolah (2017) 